\title{
The Reality of Artificial Sweeteners
}

\author{
Rafia Bano* \\ Department of Clinical Nutrition, College of Applied medical Sciences, University of Hail, Saudi Arabia
}

Submission: April 04, 2018; Published: May 09, 2018

*Corresponding author: Rafia Bano, Department of Clinical Nutrition, College of Applied medical Sciences, University of Hail, HAIL, KSA, Saudi Arabia, Email: rafiazafar78@gmail.com

\begin{abstract}
Now a days we are facing serious obesity issues worldwide. More than half of people in the US are becoming overweight, of which more than half are obese. As a result the weight related disorders are on the rise. So with all of these weight related problems going around, increased number of people struggling with weight lost regimens. They are trying to change their eating habits to include more vegetables and whole grains in their diets. They're trying to be more physically active. They're trying to modify snacking choices to healthier ones.

There has been found an increasing trend of substituting artificial sweeteners in the sweet snacks and drinks that make up the majority of the American diet. But the question is that - are these substitutes really going to help? Or are they going to do more harm than benefit? The research has shown mixed evidences, but more and more is showing that these artificial sweeteners are not a good substitute. Artificial sweeteners continue to be a controversial public health issue, and the research keeps coming. At one side, many people are strongly opposing the use of artificial sweeteners because of the reported connections with increased risk for cancer and other metabolic and degenerative diseases. While on the other side, artificial sweeteners are becoming more and more popular as people try to minimize calorie consumption to lose weight.

Increasing evidences are coming up through researches to cover comprehensively in a blog article, but the present article will try to cover the basics: are these artificial sweeteners really linked to cancer or other diseases? Do they really help with weight loss, or do they only give harm? And finally, Is it a right decision to include them in your diet?
\end{abstract}

Keywords: Artificial sweeteners; Diet; Sucralose; Aspartame; Additive; Metabolism.

\section{Introduction}

While manufacturers of artificial sweeteners claim that their products are safe, these are actually linked to many side effects. Aspartame goes by the brand names NutraSweet and Equal and is 180 times as sweet as sugar. At the end of 2008, aspartame was found in over 6,000 products. The approval process for aspartame was said to have been riddled with scandal, bribes, and other shady dealings within the pharmaceutical industry, large American corporations, and the FDA. Initially, the FDA strongly denied the approval of aspartame products. Due to political ties and regulatory tricks, aspartame was finally approved in 1983

Less than a year later, the FDA had recorded 600 consumer complaints of headaches, dizziness, and other health-related reactions from aspartame consumption. Other problems linked to aspartame consumption include weight gain, vision problems, depression and mood changes, and brain cancer.

\section{The two most concerning artificial sweeteners}

There are five dangerous sugar substitutes that are approved for consumer use: saccharin, neotame, acesulfame potassium, aspartame, and sucralose. Of the five main artificial sweeteners, sucralose and aspartame are the most pervasive and dangerous substitutes found in products on store shelves today.

Sucralose: This artificial sweetener is marketed under the name Splenda. Sucralose is originally denatured sucrose. The preparation includes chlorinating sucrose, the structure of the sugar molecules are chemically changed by replacing three chlorine atoms for three hydroxyl groups [1]. Chlorine a known carcinogen, so this is the question that why the FDA is allowing these known toxic materials to be included in our foods and beverages?

It is still not clear as to why the FDA approved sucralose to be used in food products after knowing the nature of chlorine. It should also be there in the public's knowledge that it was approved even after getting the results of the research which revealed possible toxicity of the substance. There have been no longitudinal researches on the effects of sucralose. The same was the case with tobacco. As a result of not getting enough evidences from epidemiological research, it took many years to follow up the dangerous effects of smoking cigarettes. It's unfortunate and 
confusing that the same mistakes are being repeated even after getting the initial negative indications, checks and balances that are now in place. If the FDA is not going to take any steps in and make monitoring and research possible and mandatory, then we can't predict the safety of these substances, including food items.

Aspartame: This artificial sweetener is marketed under the names Equal and NutraSweet and there are thousands of other everyday products that contain this chemical, too. Just to name a few for example: yogurt, sodas, pudding, table sugar substitutes, chewing gum, bread, etc [2]. Once the statute of limitations ran out and the product was once again under consideration, many discrepancies were highlighted between the reported and actual findings.

Consumers are increasingly complaining about NutraSweet, to the extent of " $80 \%$ of all complaints about food additives," but another researcher reported that the FDA has yet to take decision on any of them. Irrespective of this negligence by the FDA, there are indications that this sweetener is toxic. According to a researcher Ms. Martini, in a report from Flying Safety, an official United States Air Force publication, The US pilots were warned not to include Aspartame in any of the food items at all. What was the reason to this? Because "Aspartame has been investigated as a possible cause of brain tumors, mental retardation, birth defects, epilepsy, Parkinson's Disease, Fibromyalgia, and Diabetes" [3] and the FDA has made no action to regulate this toxic substance.

\section{An accident waiting to happen: the birth of aspartame}

Like an omen, aspartame was discovered in 1965 entirely by chance. That's right ... by mistake.

One scientist G.D. Searle chemist James was working in his laboratory trying to invent a drug to treat peptic ulcer disease. The story started as he accidentally spilled one of the chemicals he was using onto his hand. He licked his finger to clean, and while doing so came to discover the sweet taste of the aspartame that he had spilled [4]. This is the beginning story of what has become now as one of the most potentially dangerous and controversial artificial food additives in human history.

\section{Timing is everything}

Researches on aspartame were on the rise just after another artificial sweetener cyclamate was out of the U.S. market and saccharin was under critical examination. The disappearance of cyclamate left a void it appeared saccharin may not be able to fill. At the time when cyclamate was banned, the "diet" market costs a $\$ 1$ billion dollar per year in the U.S for advertising [5]. Manufacturers of diet products were very much confused to find a substitute product that would make sure they spare not a dollar of that amount on the table.

\section{What is aspartame, exactly?}

Aspartame is marketed by the brand names NutraSweet and Equal. It is one of the first generation of artificial sweeteners and is 180 times sweeter than sugar. At the end of the year 2008, aspartame was used in the production of over 6,000 products including carbonated soft drinks, chewing gum, confectionaries, gelatins, dessert mixes, puddings, frozen desserts, table sweeteners, and sugar free cough drops.

Products containing aspartame are in the market in over 100 countries and are included in the diet of over 250 million people across the globe. The scientific name for aspartame is 1-aspartyl 1 phenylalanine methyl ester. There are three components present:

1. Phenylalanine which makes up 50 percent of the chemical by weight

2. Aspartic acid -which makes 40 percent

3. Methanol (wood alcohol) -making 10 percent

\section{Are your health problems related to artificial sweeteners' consumption?}

You may not be aware that you are having a reaction to artificial sweeteners. In fact, majority of the people can't make a connection, and an enormous amount of time and money is spent by them, trying to find out why they are getting a health problem. To determine whether you have a sensitivity or reaction, you have to exclude all sorts of artificial sweeteners from your food. If you are consuming aspartame through caffeinated drinks, you will have to slowly decrease your intake so as to avoid caffeine withdrawal symptoms. After one to two weeks of being free from artificial sweetener, notice how do you feel, especially as compared to when you were having the sweeteners.

In case you don't notice any remarkable difference in your feelings, it may be because you are able to tolerate aspartame acutely, which means that your body will not give an immediate, adverse response. However, this doesn't mean your health won't get deteriorated in the long run by this chemical and its breakdown products. It is always advised to remain free from all sorts of artificial sweeteners, whether or not you notice an immediate difference in the condition of your health. If you notice a positive change in your health condition after stopping aspartame, there are chances are your body has a particular sensitivity to this toxic chemical.

Another chemical Formate, which is the waste product of formaldehyde, is reported to induce poly chemical hypersensitivity (PCS) in some individuals. If your body develops high sensitivity to multiple chemicals, you may not be able to tolerate relatively low exposure to preservatives, perfumes and other substances, many of which are unavoidable as you go out for your routine activities. Whether or not you have high sensitivity to aspartame, you should keep in mind that aspartame is fully metabolized by the human body, and its byproducts can impose a serious risk to your health. There are reports of neurological damage occurring from long-term use of aspartame. 


\section{Current Research in Diabetes \& Obesity Journal}

\section{Cancer}

Artificial sweeteners were initially linked to risk of cancer in the 1970's after a research study concluded that both saccharin and cyclamate (used previously as artificial sweetener) combined were found to caused bladder cancer in rats. The process behind these effects was afterwards studied to be précised to rats only and could not be generalized to other organisms like animals or humans, because it was found that in these rats, doses of vitamin $\mathrm{C}$ were also found to be the risk factor for bladder cancer, and further researches have demonstrated that none of these sweetener is causing cancer $[6,7]$.

However, the present study deepens the doubt over artificial sweeteners, and thanks in part to the media's liking for blowing things way out of proportion, the status of artificial sweeteners has never revealed. Later another research study reported a connection between aspartame consumption and brain tumors. The researchers coined this hypothesis on the basis that both brain tumor and aspartame consumption had been on an rise over time since 1980 - despite the fact that he don't know whether the people reporting brain tumors did actually consumed artificial sweeteners - and on a rat experimental study in which foods fortified with aspartame led to the development of brain tumors [8]. This correlation has been somewhat discarded by another research community as they have reported that three case-control studies found no connection between brain tumors and aspartame consumption, and ensuing animal studies were unable to replicate the correlation of aspartame consumption and resulting brain tumors found in the initial rat study [9].

Consumption of artificial sweeteners are connected to the cases of lymphoma and leukemia, and one observational research found a slight association between intake of artificial sweetener and development of non-Hodgkin lymphoma and multiple myeloma in males, but this was not true for women [10]. The research authors revealed that due to the variability in their results, there isn't likely a causal connection, although it could not be figured out.

Artificial sweeteners are being experimented for connections with other types of cancers also, including breast cancer, pancreatic, stomach, colon, and endometrial, and the results showed no direct links [11]. Based on the research evidence, it could be proposed that artificial sweeteners are not a great risk factor for getting cancer, but the possibility can't be ignored and precaution should always be taken.

\section{Metabolic syndrome, diabetes and cardiovascular diseases}

The intake of artificial sweeteners have also been evident in connection to increased risk for getting metabolic syndrome and its correlated problems like diabetes and heart diseases. Various longitudinal and short term researches have attempted to figure out a uniform association with disease probability, but for every research that has found a correlation of artificial sweetener consumption with diseases like cardiovascular diseases or with diabetes, there is another controversial result giving no such correlation [12-14].

These unpredictable results should not come as a confusion, because of the intrinsic limitations of observational studies, but due to little or no clinical researches in humans to verify these hypotheses, the impact of artificial sweeteners on likelihood for these metabolic diseases remains indecisive.

\section{Pre-term delivery}

There has been issues in contemporary years over a prospective association between having a diet containing artificial sweetener during pregnancy and the risks of preterm delivery, as evident by two observational research studies published in the years 2010 and $2012[15,16]$. These researches have noteworthy limitations: the correlations were less and not directly dependent on the actual amount of intake; and all artificially sweetened drinks were not taken into account; and pregnant ladies who consume more artificially sweetened beverages also be liable to smoke more, have greater Body Mass Index, and higher socioeconomic status [17]. Although, the risk seems to be lesser, but the present study would suggest pregnant women to stay away from artificial sweeteners so as to be on the safer side.

\section{Losing weight}

For majority of the people, the first and foremost motivation for consumption of artificial sweeteners is a passion for reducing calorie intake to finally lose some weight. But the question remains - do these artificial sweeteners really help attain that goal? And also, the results are mixed. Many observational research studies have found a positive correlation of artificial sweetener consumption with being overweight, but in the present circumstances, reverse-suffering is particularly probable [18-21].

We can also assume that while it is possible that artificial sweeteners can result in weight gain in these studies, there are also chances that people who are obese are most probable to select diet beverages containing artificial sweeteners and other similar foods in an attempt to lose weight. There are also a considerable number of clinical trials doing research on the actual weight loss results of artificial sweeteners in human beings, although most of them are practically insignificant due to very short durations.

In a research trial, obese participants were given supplements of table sugar (sucrose) or artificial sweeteners for a period of 10 weeks [22]. As a result of this trial, subjects receiving the artificial sweeteners on an average accomplished a reduction in total weight, fat mass, and also the blood pressure, while on the other hand participants getting sucrose supplements gained more weight and had reported raised blood pressures.

Another study recently published on the effect of artificial sweeteners on weight loss gave surprisingly positive results: over a period of 12 weeks, subjects who were instructed to 
consume 24 ounces of artificially sweetened drinks daily actually resulted in more weight loss as compared to the participants who consumed 24 ounces of water daily [23]. (It's worth mentioning that this research was fully aided by The American Beverage Association.) Some other research trials have also shown reduction in calorie consumption and successful weight loss in subjects who used artificial sweeteners especially in the form of drinks [24-26].

Based on these confirmations, it is quite evident that artificial sweeteners could be helpful in reducing weight in some situations, at least over the short period of time. Although, because of the limited evidences based on these studies and the research results presented next, no confirm results could be drawn.

\section{Do artificial sweeteners 'confuse' the body?}

Long back in the human history, sweeteners were irretrievably linked to increase caloric density. If our sweet taste buds evolved predominantly to help us identify the sources of calorie dense food, how will our body systems react when our taste buds are persistently flooded with sweetness, but with no accompanying calorie boost?

Researches on animal models probably indicate that artificial sweeteners can diminish the natural ability to regulate caloric consumption. Rats who were given feeds containing artificial sweeteners constantly gain more weight as compared to the rats who are given glucose or sucrose [25]. Moreover, the rats did not showed a tendency to lose the extra weight, even after their feeds were returned back to glucose or sucrose to resume the calorie prognostic nature of sweet taste.

Interestingly in a research study, rats who were fed artificial sweetener named stevia put on significantly more weight as compared to the rats who were glucose fed, and more or less similar amounts of weight in the rats that were fed saccharin solutions [25]. Rats who were fed artificial sweeteners also tend to develop a weakened response to sugar containing foods. In another study, rats being fed artificial sweeteners were not able to recompense for the calories of a sugar preload by eating less food afterwards, whereas rats who had been fed natural sucrose foods recoup almost excellently for the extra calories in the preload by eating less food [26].

Rats that have been experimented with feeds containing saccharin also showed a reduced thermal effect in reaction to intake of a normal table sugar containing feed, along with higher blood glucose levels, as compared to the rats who had been fed with calorie containing glucose [27]. Moreover, rats who were fed with artificial sweetener saccharin produced less amount of GLP-1 (which has been shown in producing satiety and glucose balance) when conditioned with a natural sugar containing test feed [27].

Unluckily, although the animal researched are fairly vigorous, documentation in humans are limited. Nevertheless, two interesting researches that employed MRI to evaluate responses of brain to natural sugar sucrose solutions specify that artificial sweeteners may change the brain's reaction to sweet tastes in human subjects. In another research, individuals who eat artificially sweetened beverages on a regular basis had higher degree responses to saccharin and sucrose collectively when compared with subjects who did not consume artificial sweeteners [28].

Furthermore, individuals who do not consume artificial sweeteners responded differently to both of the saccharin and sucrose, whereas on the other hand those who consume artificial sweeteners on regular basis responded in the same way to both of the sweeteners. Another research concluded that the amygdala's response to natural sugar intake was negatively correlated to artificial sweetener use [28]. (The amygdala is part of the brain that is involved with taste-nutrient conditioning). Some Adverse Reactions to Aspartame could be concluded as headache, change in mood and vision, sleep problems, change in heart rate, memory loss, nausea and vomiting, rashes, dizziness and poor equilibrium, diarrhea, hives, fatigue and weakness and joint pain.

\section{Should You Be Eating Artificial Sweeteners?}

The conclusion seems to be a bit indecisive after seeing all these evidences, but the point for attention here is that artificial sweeteners are relatively a new invention in the human diet, and for present day modern, commercial foods, the working principle should always be "liable until proven faultless." Researchers have conducted what are actually population based experiments with the initiation of other commercial foods (for example vegetable oils rich in omega-6) because the inceptive evidence seemed favorable, and we can watch how good that comes up.

In spite of some successful short-term researches concerning weight loss, the probable curative and beneficial effects of artificial sweeteners have not been indicated clearly enough thus a long way to warrant extensive consumption, especially in the case when conflicting correlation with risk of diseases and the controversial impact on appetite and weight management. Eventually, while artificial sweeteners are probably not as alarming as some might consider, they should not be approve to be including your diet.

\section{References}

1. AlDeeb OA, Mahgoub H, Foda NH (2013) Sucralose. Profiles Drug Subst Excip Relat Methodol 38: 423-462.

2. Cipelli P (2017) The Lowdown on sweet? The New York Times, USA.

3. Mawhinney DB, Young RB, Vanderford BJ, Borch T, Snyder SA (2011) Artificial sweetener sucralose in U.S. drinking water systems. Environ Sci Technol 45(20): 8716-8722.

4. Wikipedia, The Free Encyclopedia, Aspartame (Accessed 2/20/09).

5. Roberts HJ (2001) Aspartame disease: an ignored epidemic. Sunshine Sentinel Press, 2001/James Turner, The Aspartame/NutraSweet Fiasco, West Palm Beach, USA. 


\section{Current Research in Diabetes \& Obesity Journal}

6. Weihrauch MR, Diehl V (2004) Artificial sweeteners-do they bear a carcinogenic risk? Ann Oncol 15(10): 1460-1465.

7. Olney JW, Farber NB, Spitznagel E, Robins LN (1996) Increasing brain tumor rates: is there a link to aspartame? J Neuropathol Exp Neurol 55(11): 1115-1123.

8. Schernhammer ES, Bertrand KA, Birmann BM, Sampson L, Willett WC, et al. (2012) Consumption of artificial sweetener- and sugar-containing soda and risk of lymphoma and leukemia in men and women. Am J Clin Nutr 96(6): 1419-1428.

9. Sievenpiper JL, de Souza RJ (2013) Are sugar-sweetened beverages the whole story? Am J Clin Nutr 98(2): 261-263.

10. Marinovich M, Galli CL, Bosetti C, Gallus S, La Vecchia C (2013) Aspartame, low-calorie sweeteners and disease: regulatory safety and epidemiological issues. Food Chem Toxicol 60: 109-115.

11. Swithers SE (2013) Artificial sweeteners produce the counterintuitive effect of inducing metabolic derangements. Trends Endocrinol Metab 24(9): 431-441.

12. Halldorsson TI, Strøm M, Petersen SB, Olsen SF (2010) Intake of artificially sweetened soft drinks and risk of preterm delivery: a prospective cohort study in 59,334 Danish pregnant women. Am J Clin Nutr 92(3): 626-633.

13. Blaylock RL (2006) Excitotoxins: the taste that kills. Health Press (NM), USA.

14. (2004) Artificial sweeteners -more dangerous than you ever imagined. Eur Heart J 25(16): 1412-1418.

15. Englund Ögge L, Brantsæter AL, Haugen M, Sengpiel V, Khatibi A, et al. (2012) Association between intake of artificially sweetened and sugarsweetened beverages and preterm delivery: a large prospective cohort study. Am J Clin Nutr 96(3): 552-559.

16. Marinovich M, Galli CL, Bosetti C, Gallus S, La Vecchia C (2013) Aspartame, low-calorie sweeteners and disease: regulatory safety and epidemiological issues. Food Chem Toxicol 60: 109-115.

17. Gardner C (2014) Non-nutritive sweeteners: evidence for benefit vs. risk. Curr Opin Lipidol 25(1): 80-84.

This work is licensed under Creative Commons Attribution 4.0 Licens DOI: 10.19080/CRDOJ.2018.07.555708
18. Pereira MA, Odegaard AO (2013) Artificially sweetened beverages-do they influence cardiometabolic risk? Curr Atheroscler Rep 15(12): 375 .

19. Swithers SE (2013) Artificial sweeteners produce the counterintuitive effect of inducing metabolic derangements. Trends Endocrinol Metab 24(9): 431-441.

20. Raben A, Vasilaras TH, Møller AC, Astrup A (2002) Sucrose compared with artificial sweeteners: different effects on ad libitum food intake and body weight after $10 \mathrm{wk}$ of supplementation in overweight subjects. Am J Clin Nutr 76(4): 721-729.

21. Peters JC, Wyatt HR, Foster GD, Pan Z, Wojtanowski AC, et al. (2014) The effects of water and non-nutritive sweetened beverages on weight loss during a 12-week weight loss treatment program. Obesity (Silver Spring) 22(6): 1415-1421.

22. De La Hunty A, Gibson S, Ashwell M (2006) A review of the effectiveness of aspartame in helping with weight control, nutrition bulletin 31(2): 115-128.

23. Tate DF, Turner McGrievy G, Lyons E, Stevens J, Erickson K, et al. (2012) Replacing caloric beverages with water or diet beverages for weight loss in adults: main results of the Choose Healthy Options Consciously Everyday (CHOICE) randomized clinical trial. Am J Clin Nutr 95(3): 555-563.

24. Swithers SE, Martin AA, Davidson TL (2004) High-intensity sweeteners and energy balance. Physiol Behav 100(1): 55-62.

25. Davidson TL, Swithers SE (2012) A Pavlovian approach to the problem of obesity. Int J Obes Relat Metab Disord 28(7): 933-935.

26. Swithers SE, Laboy AF, Clark K, Cooper S, Davidson TL (2012) Experience with the high-intensity sweetener saccharin impairs glucose homeostasis and GLP-1 release in rats. Behav Brain Res 233(1): $1-14$

27. Green E, Murphy C (2012) Altered processing of sweet taste in the brain of diet soda drinkers. Physiol Behav 107(4): 560-567.

28. Rudenga KJ, Small DM (2012) Amygdala response to sucrose consumption is inversely related to artificial sweetener use. Appetite 58(2): 504-507.

\section{Your next submission with Juniper Publishers will reach you the below assets}

- Quality Editorial service

- Swift Peer Review

- Reprints availability

- E-prints Service

- Manuscript Podcast for convenient understanding

- Global attainment for your research

- Manuscript accessibility in different formats

( Pdf, E-pub, Full Text, Audio)

- Unceasing customer service

Track the below URL for one-step submission https://juniperpublishers.com/online-submission.php 